\title{
FILOSOFÍA Y POLÍTICA: UN LUGAR DE ORIGEN DE LA DISTINCIÓN ENTRE CIENCIAS NATURALES E HISTÓRICO-SOCIALES
}

\author{
Luis F. Aguilar Villanueva \\ Facultad de Gencias Polficas $y$ Sochales \\ Universidad Nacionai. Autónoma de México
}

Este escrito, que tiene todas las características de ir a la búsqueda de un "estado de la cuestión" en la filosofía moderna, parte del supuesto que el proceso de formación de la distinción conceptual entre naturaleza e historia, empiria y "espíritu", physis y cultura, causalidad y teleología en las ciencias histórico-sociales, está íntimamente relacionado con el proceso de formación de la distinción entre filosofía y política. Para los filósofos que observan de cerca el estado y desarrollo de la sociologia clásica y contemporánea es una evidencia casi elemental el hecho de que la sociología se mueve dentro de una tensión irresuelta: si debe ser una ciencia "explicativa" o una ciencia "comprensiva", si debe explicar por causas o por fines ("sentido de la acción"), hipotética o hermenéutica.

La tradición gnoseológica y metodológica alemana del siglo xx dedicó inolvidable esfuerzo a la solución de esta cuestión y condicionó decisivamente el planteo pasado y presente del problema. Historicismo, marxismo y neokantismo, a pesar de su proximidad temporal, son ya ejemplos clásicos en el tratamiento del problema. Es así que se discute, a veces improductivamente, en torno de la posibilidad y validez de la distinción entre "ciencias de la naturaleza" y "ciencias del espíritu" (de la cultura, del hombre), así como en torno de una presunta o exigida arquitectura original de la epistéme y del método de estas últimas. Se argumenta de varias formas y desde diversos supuestos que las ciencias relacionadas con la vida social y política no pueden sino hacer necesaria referencia a la intencionalidad o al libre sentido de individuos, grupos o colectividades y, por ello, rebasan cualquier intento de empujarlas hacia esquemas de hipótesis causales, particularmente si son deterministas.

Empero, la reconstrucción teórico-histórica del debate en torno al método de las ciencias sociales muestra casi enseguida que la cuestión politica, la cuestión de la relación entre ciencia (filosofía) y política, está presente y hasta interpolada en la cuestión metodológica (o epistemológica) de las ciencias sociales. En efecto, es suficientemente constatable y argumentable que la fundación de la nueva ciencia social va del 
brazo con la función de la nueva política. Más aún y con validez particular para el caso de Alemania, se puede afirmar que el imponente recorrido de la inteligencia alemana del siglo xrx es un largo y difícil desplazamiento teórico desde la filosofía a la ciencia social, que se articula con el aun más fatigoso desplazamiento político de Alemania hacia su constitución como Estado-Nación.

Este escrito quiere, entonces, señalar, más que demostrar, cómo la distinción entre naturaleza e historia, explicación y comprensión, determinismo y teleología, se insertan dentro de un "estado de la cuestión" que es más amplio y fluido, el de la relación entre filosofía y política. Para ello se hace un memorandum de Kant y Hegel, que influyeron decisivamente dentro de la tradición alemana en el planteo y la línea de solución acerca de la posibilidad, originalidad y límites de la ciencia histórico-social.

El escrito, aquí y allá, despertará la más que justificada apreciación de "cabos sueltos", pero advierto al lector que es sólo el momento propedéutico de una investigación más rigurosa y documentada sobre la gnoseología y metodología del historicismo neokantiano en las ciencias histórico-sociales, en particular sobre la obra de Max Weber, que ha sido un aporte muy importante para la configuración y fundamentación de la sociología y la historiografía.

\section{Revolución burguesa y razón ilustrada}

El idealismo alemán ha sido considerado como Teoría de la Revolución Francesa. Esto no significa que Kant, Fichte, Schelling y Hegel ofreciesen una interpretación teórica de la Revolución francesa, sino que en gran parte escribieron su filosofía como respuesta al reto de Francia de reorganizar el Estado y la Sociedad sobre una base racional, de modo que las instituciones sociales y políticas concordaron con la libertad y el interés del individuo. A pesar de su agria crítica al Terror, los idealistas alemanes dieron unánimemente la bienvenida a la Revolución, llamándola aurora de la nueva era, y todos relacionaron los principios básicos de su filosofía con los ideales que ella representaba... Por consiguiente, las ideas de la Revolución francesa están presentes en el propio núcleo de los sistemas idealistas y determinan en gran medida su estructura conceptual. ${ }^{1}$

Es innegable que el hecho de la Revolución francesa fue entendido o interpretado por sus protagonistas, espectadores y opositores como el punto de conjunción entre teoría y práctica, razón y realidad, filosofía

1 H. Marcuse, Razón y Revolución. Alianza Editorial, Madrid, 1971, p. 9. 
y sociedad. La Revolución era el acontecimiento histórico sin más, porque por primera vez en la historia del hombre se lograba la humanización de la historia, su "racionalización" e "ilustración", así como la identidad entre el pensar y el ser, la lógica y la cronología, la verdad y la existencia. Por primera vez, en 1789 , la filosofía del sujeto obtenía realidad o, dicho más específicamente, los principios del derecho natural racional abstracto lograban su existencia social concreta. Por y en el acto político la sociedad se transformaba en hecho de razón y la razón en hecho social, el objeto en sujeto y el sujeto en objeto.

Este entendimiento filosófico de la revolución burguesa como "hecho de razón" y "fuerza de la razón" significaba simultáneamente un entendimiento de la revolución burguesa como "el hecho filosófico" y "la fuerza de la filosofía". La revolución burguesa era "la positivación del derecho natural como realización de la filosofía" (J. Habermas), la sociedad llegada a su concepto verdadero (el concepto de la naturaleza humana) y el concepto verdadero de sociedad llegado a su realidad sociohistórica efectiva. Por esto mismo, el hecho revolucionario francés no era sólo algo particular y contingente, "nacional", sino un acto universal y necesario, mundial y humano: el inicio de la era del hombre o de la edad de la razón, el inicio de la sociedad verdadera. De aquí nace la moralidad incondicional de la revolución y el imperativo moral de su difusión universal, sin fisuras y sin concesiones.

Esta relación íntima entre la filosofía y la revolución burguesa obligaba a la conciencia a plantearse el problema de la relación entre filosofía y política, teoría y praxis, razón e historia. Fue por ello que las posiciones políticas asumidas ante la revolución se tradujeron congruentemente en posiciones de teoría del conocimiento. De igual manera, las proposiciones teóricas gnoseológicas en torno a la relación entre sujeto de conciencia y realidad empírica definieron las posturas políticas en favor o en contra de la revolución burguesa. Kant y Hegel, Marx y el historicismo alemán, lo atestiguan.

\section{Revolución francesa y Revolución copernicana}

El interés de Immanuel Kant (1724-1804) por la política nace a partir de la Revolución francesa, precisamente cuando el cuerpo de sus dos tareas críticas, Crítica de la razón pura (1781-1787) y Crítica de la razón práctica (1788), estaba ya perfectamente terminado.

El curso de la realidad francesa, en cuanto revolución del absolutismo y construcción crítica del Estado, apegada a las exigencias de razón y libertad, era en verdad semejante al discurso de la razón kantiana como crítica y revolución de la metafísica y como imperativo de factualidad 
social para la libertad, para la ley moral. Kant percibió rápidamente la vinculación histórica entre el programa de la Revolución francesa y el programa de su "revolución copernicana". En ambos programas los objetos prácticos y los objetos cognoscitivos de experiencia deben girar en torno al sujeto libre práctico y teórico, libre en tanto autodeterminador de esa materia disponible para el hombre, que es la historia social y la naturaleza: "la experiencia". Las dos revoluciones, la francesa y la suya, significan ganar de nuevo el principio de creación extraviado, el Hombre-Sujeto como principio de producción del "mundo", como hacedor del discurso teórico y del curso práctico de la realidad social y natural. Los astros de la sociedad y la naturaleza se modelan y regulan de acuerdo con el sujeto que los trasciende y atrae, que los recoge y trabaja, los ordena y les da significación, significación teórica por "el concepto" y significación práctica por "el fin": por la ley natural y por la ley moral. Lo que el sujeto crítico-trascendental de Kant y el sujeto revolucionario-político de Francia descubren, entienden y valoran acerca de sf mismos, lo que constituye su autoconciencia, es justamente su capacidad de producir teórica y prácticamente "mundo": la sociedad histórica y la naturaleza. Por esto, autoconciencia del sujeto (autodeterminación) y revolución del objeto social-natural (determinación) constituyen la instancia de Kant y el movimiento del 89.

Más aún, la autoconciencia y la autodeterminación del sujeto tienen su expresión operativa en el acto de la revolución, así como Ia autoconciencia y la autodeterminación de la revolución tiene su condición de posibilidad en la existencia y acción del sujeto. Por esto, Kant creyó ver interpretativamente que su sujeto trascendental gnoseológico y moral se actuaba en el sujeto histórico revolucionario francés, que su filosofía del sujeto se expresaba efectivamente en el movimiento político de la Constituyente y que, en suma, por la revolución la filosofía se transformaba y se constituía en realidad social e histórica, en política.

En la intención y la tentativa revolucionaria de actuar de acuerdo con la teoría de realizar el concepto, Kant ve el movimiento de la filosofía teórica que deviene sociedad política. Los hechos franceses representaban los esfuerzos del hombre por salir de su "estado culpable de minoría de edad", de sinrazón y de patria potestad enajenante, y por entrar en su "edad de razón" y autodirección racional, audaz y fatigoso tránsito histórico en el que se realiza y expresa la sustancia de la ilustración emancipadora.

La ilustración es la salida del hombre de su estado culpable de minoría de edad. La minoría de edad, la inmadurez, consiste en que el hombre es incapaz de servirse de su razón sin la dirección de otro. Y la culpabilidad consiste en que la causa de la inmadurez no está 
en un defecto de la razón sino en una falta de decisión y osadía. El lema de la ilustración es: Sapere audel, osa servirte de tu propia razón. ${ }^{2}$

La Francia del 89 era justamente la osadía de la razón en acción, la emancipación de la razón y la razón emancipadora en un único movimiento, la determinación de sacudirse direcciones externas y extrañas a la razón y de conducirse únicamente según sus principios y conceptos, la decisión del pensar como el nacimiento histórico de la libertad-autonomía racional y, con ella, el nacimiento de la historia humana en su sentido auténtico. La decisión de pensar por sí misma, la gnoseología trascendental, era la base de la autogestión racional, de la política republicana. Esta interpretación revolucionaria de la razón y racional de la revolución, ya apuntadas por Kant en sus dos escritos de 1784, Ideas para una historia universal desde el punto de vista cosmopolita y Respuesta a la pregunta: ¿Qué es la ilustración?, parecían encontrar por primera vez su laboratorio en los acontecimientos franceses. Pero, sobre todo, sus dos críticas de la razón caminaban irresistibles en la misma dirección de los revolucionarios. La crítica de la razón destruía desde sus cimientos la plataforma de sostén de la dominación tradicional absolutista, su fundamento teológico y/o su fundamento factualista (contractualista), de la misma manera que la razón crítica, desde la razón y en nombre de ella, asumía la tarea de construir la dominación racional republicana, postulando factualidad social para la libertad moral en un intento forzosamente inacabado de traducirla y mediarla jurídica y políticamente.

La primera tarea de la razón pensante según sus propios principios, la crítica destructiva, fue un enjuiciamiento de sí misma en su uso cognoscitivo puro y su resultado fue negarle a la razón cualquier posibilidad metafísica o realista y así la capacidad real de constituirse y acreditarse teóricamente como "facultad del incondicionado" (Vermögen des Unbedingten), del Absoluto. De esta manera, y sobre la sola base de los resultados gnoseológicos, Kant criticaba e invalidaba la posibilidad de demostración racional de la existencia y la esencia del referente divino del absolutismo político: la crítica de la razón pura sacudía la teoría del monarquismo, mostrando la indemostrabilidad de su teoría. En efecto, absolutismo político y teoría metafísica eran históricamente necesarios el uno para el otro: el absolutismo era la condición política de la existencia y validez social de la teología natural: la metafísica era la condición teórica de la existencia y validez política de la monarquía incondi-

2 I. Kant, "¿Qué es Ilustración?", en Filosofia de la Historia, 3 ed., FCE, México, 1979, p. 25. 
cionada. En este sentido, la destrucción teórica del Absoluto, del incondicionado, llevada a cabo por la dialéctica trascendental de la razón pura, dejaba sin sus condiciones necesarias de validez gnoseológica a la metafísica, a la teología, y de validez ideológico-política a la monarquía. En cambio, la segunda tarea, la crítica constructiva, concluyó su enjuiciamiento de la razón en su uso práctico constituyéndola en la "Facultad del Incondicionado", en la pura facultad de producción a priori, a partir de sí misma, de normas absolutas para la acción humana (del "deberser" absoluto), y por tanto en la facultad que debe postular las condiciones necesarias reales para tan pura y sublime práctica incondicionada, a saber, la existencia de la libertad (en sentido positivo) y de su causalidad propia en la historia, por ende, la existencia de un mundo puramente inteligible (inmortalidad del alma) y de Dios como Sumo Bien. La razón práctica sólo puede ordenar imperativamente $y$, por tanto, exigir incondicionalmente la identidad entre libertad y realidad, valor $y$ hecho, deber-ser racional y ser social, moral y política. Este imperativo de una necesaria identidad no es demostrable y es hasta contradictorio científicamente, si se le quiere fundamentar con base en el uso cognoscitivo de la razón pura, pero, a pesar de su indemostración y hasta contradicción científica, es obligatorio absolutamente para una práctica racional (humana) que sea auténticamente tal.

Lo que Kant interpreta y aprecia en el movimiento revolucionario francés es precisamente esta postulación, necesariamente implícita en el imperativo categórico de la razón, de que debe haber una identidad entre el concepto puro de libertad y las instituciones sociales, entre la exigencia incondicional de libertad y la sociedad que condiciona la libertad, entre lo que debe ser la sociedad propia y verdadera del hombre racional y lo que la sociedad de hecho es (mera región de las pulsiones del poder, el placer y la utilidad), entre la pura ley moral y el interesado hecho contractual. La revolución es sustancialmente la postulación de una necesaria y congruente identidad entre la moral categórica, el poder político y la sociedad civil (empírica) de las necesidades materiales. La revolución es el intento histórico más coherente, a pesar de sus reflujos y contradicciones, de obedecer al principio incondicionado de la moral racional pura y de traducirlo jurídica y políticamente. La revolución es la ruptura decidida con las direcciones políticas de la fe eclesiástica tradicional y con las fundamentaciones contractualísticas de mera subordinación al Leviatán absoluto o de bruta finalidad utilitarista y eudemonista.

Aquí se ve mejor de qué naturaleza era la adhesión de Kant al espíritu de la Revolución francesa. Cuando los políticos de viejo estilo 
acusaban a los revolucionarios por su doctrinarismo abstracto (acusación que en los teóricos románticos se convertirá en un reproche por haber olvidado la historia), querían decir que las teorías revolucionarias, como un instrumento de acción, adolecían de la adaptación necesaria a la realidad de hecho, para ser aplicables de manera ventajosa. Kant, al contrario, cuando aprecia el intento revolucionario de actuar según la teoría, entiende la teoría como un conjunto de principios morales determinados a priori, cuya aplicabilidad a la experiencia no es demostrada sino postulada... Este tipo de planteamiento aleja definitivamente la doctrina de Kant respecto a las concepciones acostumbradas de la política, que ponen el objetivo de ésta en el bienestar individual o colectivo. En cambio, una política subordinada al derecho no busca directamente la felicidad, aunque pueda favorecerla indirectamente. ${ }^{3}$

En suma, la crítica de la razón pura sepulta el absolutismo apuntalado teológicamente, así como la crítica de la razón práctica sepulta tanto al absolutismo, como a un republicanismo basado sólo en un contractualismo de hecho, en un pacto social particular y contingente, movido exclusivamente por un mero cálculo psicológico o económico de utilidades privadas (paz, seguridad, propiedad, ganancia), en un pacto social del que emanan leyes condicionales y no por una ley incondicional del que deriva obligatorio el pacto social.

Desde la perspectiva kantiana, la política cabalmente humana sólo puede y debe fundamentarse en la moral racional, en la imperatividad absoluta y universal de la razón, mediada jurídicamente. Pero exigir la articulación obligatoria entre moral y política comporta y supone haber establecido veritativamente la existencia de la voluntad libre y la eficacia de sus actos en la historia; significa suponer que la libertad puede y debe intervenir e incidir en el mundo natural y social, para innovarlo y transfigurarlo de acuerdo con las normas racionales del derecho y la moral. Todo esto, en el fondo, implica afirmar que la razón libre posee una causalidad propia, que los fines de la voluntad libre pueden y deben ser las causas de la historia social (que incluye la relación del hombre con la naturaleza), así como reconocer que el "deber-ser" moral puede determinar causalmente el "ser" social. Sin embargo, este presupuesto de una causalidad propia de la libertad en la historia social sólo puede ser un postulado indemostrable racionalmente y no una hipótesis demostrable. De todos modos, la moral y la política se constituyen como tales en cuanto postulan una "causalidad propia" (eigene Kausalität) de la razón práctica o voluntad libre en la historia: se constituyen sólo por el reconocimiento postulatorio de que los fines del hombre son las reales

3 V. Mathieu, Kant, en Storia delle idee politiche, economiche e sociali. Vol. IV, UTET, Torino, 1975, p. 751. 
causas de la historia, de que la significación es la causalidad. Sin esta postulación no hay sujeto trascendental por sobre la experiencia socionatural. $\mathrm{Y}$ sin trascendentalidad del sujeto no hay ni moral ni derecho ni política racional estricta. No hay historia en sentido auténtico y estricto, ni revolución.

\section{Fines y causas, valores y hechos}

La filosofía crítica llegó al resultado de fundamentar sólo la posibilidad de conocer racionalmente, científicamente, la naturaleza. La ciencia físico-matemática, que no la metafísica, cae dentro del ámbito del conocimiento racional posible. La fundación histórica de la física en Galileo, Kepler, Newton, encuentra así en Kant su fundamentación teórica. La contingencia histórica del surgimiento de una ciencia encuentra en la filosofía crítica su absolutez gnoseológica, su validez necesaria y universal. Ahora bien, para la razón pura crítica, no hay posibilidad de ciencia sin conocimiento "extensivo", sin juicios que, a diferencia de los juicios "analíticos", pongan y añadan nuevas determinaciones al objeto de experiencia conceptualizado, que éste de suyo no lleva implicadas o incluidas en el contenido lógico de su concepto: no hay posibilidad de ciencia sin "juicios sintéticos". Más aún, la ciencia resulta imposible si las nuevas determinaciones puestas no muestran que mantienen una "conexión necesaria y universal" con el objeto de experiencia conceptualizado: sin juicios sintéticos a priori.

La ciencia debe ser una actividad de conciencia a priori, porque la validez necesaria y universal, incondicionada, de la vinculación entre las determinaciones nuevas y el objeto de experiencia - la "ley"- no puede derivarse de la mera experiencia, sumergida puntualmente en la particularidad y la contingencia (a posteriori). Si la ciencia es conocimiento de leyes, debe necesariamente tener su condición de posibilidad y validez en el apriori, en un más allá de la pura empiria, en una dimensión "independiente de la experiencia" y anterior a ella; el apriori es la misma estructura de la acción de la razón, su innata y espontánea manera de conocer (elaborar) los objetos dados por la experiencia. Sin esta fundamentación apriorista, "trascendental", ("formas de la intuición", "categorías", "principios", "yo pienso") la dispersa y fluida variedad de las representaciones sensoriales no podría ordenarse y transformarse en la "unificación y síntesis" que es propia del concepto y del enunciado, menos aún establecer una "conexión necesaria" entre las representaciones, es decir, no se podría obtener "conocimiento" y "conocimiento científico", "concepto" y "ley". No habría ni acto ni "objeto" de cono- 
cimiento en sentido propio y estricto, sino una masa indiferenciada de sensaciones sin referencia y atribución.

Conviene e importa también destacar el resultado final al que llega la gnoseología trascendental ("analítica de los conceptos" y "analítica de los principios"). Ésta termina su recorrido, afirmando el determinismo de la naturaleza y de la historia fenoménica, el determinismo de todo lo que cae dentro del mundo de la experiencia espacio-temporal conceptualizada. Nada puede ser conocido como objeto, si el entendimiento (Verstand) no realiza en torno a él un ordenamiento que unifique la dispersión y multiplicidad de sus representaciones, si no llega él a ser "unificación, síntesis de lo múltiple" (Vereinigung, Zusammensetzungdes Mannigfaltigen), punto de fusión necesaria de todo el conjunto de las varias determinaciones recogidas y expresadas por las representaciones puntuales y efímeras de la experiencia sensible. De la misma manera, nada de lo que acontece en la dimensión del tiempo puede ser conocido en sentido propio y estricto, si la multiplicidad de sus varias representaciones sucesivas, referidas a la secuencia temporal de los varios estados del proceso de su acontecimiento, no es reunida en torno a una secuencia necesaria bien determinada, a una unívoca relación causal, a la unidad de la causa: "El principio de la sucesión temporal según el principio de causalidad". La razón ligada a la experiencia sensible y réferida a fenómenos sólo puede conocerlos según un esquema de determinación causal, según leyes. La razón posible, es decir, la inteligencia científica, puede únicamente afirmar que todo lo que sucede y puede suceder dentro del ámbito de la experiencia es universal y necesariamente un "efecto", totalmente predeterminado por hechos antecedentes que son su "causa". Este encapsulamiento necesario y universal del pensar dentro de los límites de la fenomenicidad y de la causalidad, si bien pone la equivalencia entre cientificidad, causalidad y fenomenicidad, plantea sin embargo a Kant el serio problema teórico acerca de la posibilidad y la especificidad de la ciencia politica y social y el aún más grave problema práctico acerca de la posibilidad de existencia de una politica centrada en la libertad y la emancipación. ¿Hasta dónde su revolución copernicana teórica, que termina en la proposición del determinismo en el conocimiento de los fenómenos, contradice a su pasión por la revolución francesa política que da comienzo y expresa la causalidad de la libertad humana en la historia? ¿Causalidad determinista o libre?

En efecto, todas las acciones políticas, sociales, económicas que constituyen la historia humana son hechos y, como tales, datos de experiencia espacio-temporal. Por tanto sólo pueden ser conocidos determinísticamente, como hechos-efectos necesariamente originados por otros hechos-causas: la Historia sólo puede ser conocida como Naturaleza. La oscura y 
fría conclusión es que no se puede conocer ni afirmar la posibilidad de un espacio para la libertad humana dentro del horizonte de experiencia, dentro del mundo socionatural. En el nivel del conocimiento científico, la causalidad soberana de la libertad resulta desconocida, es imposible de ser afirmada. Cognoscitivamente no hay espacio para la moral imperativa de libertad ni para una política centrada en la realización cabal de la libertad. No se puede racionalmente afirmar que la historia social sea producto, esté siendo producida y pueda ser producida por la libertad, por la libre iniciativa del sujeto que, de acuerdo con sus propios e incondicionales fines, intenta transformar sociedad y naturaleza. Al contrario, los fines del sujeto podrán ser conocidos sólo como efectos de causas objetivas. La única cognoscibilidad de los fines del sujeto, del "sentido de su acción", es su cognoscibilidad por causalidad y, por tanto, su no poder ser conocidos como fines sino como efectos. El conocimiento implica la reducción de los fines libres a efectos necesarios. La historia social, pues, está engarzada y conectada por el determinismo objetivo y no por la teleología del sujeto. El precio gnoseológico del método trascendental es reducir las acciones de los sujetos racionales a objetos de experiencia. Esto parece llevar paradójicamente a la imposibilidad de demostrar racionalmente la posibilidad real, histórica, de una revolución política ilustrada y moral.

Pero para el paradójico Kant esta conclusión no es la única, ni la ideológicamente deseada. Los hechos humanos sociohistóricos, que se nos ofrecen en la experiencia conceptualizada como efectos necesarios, nos muestran sólo un aspecto de su realidad, el aspecto con el cual pueden necesariamente manifestarse a la razón apriorista, ordenadora y unificadora del tiempo: su aspecto "fenoménico" precisamente. Sin duda, los hechos sociales, en cuanto objetos de experiencia, quedan condicionados en su posibilidad de conocimiento por nuestra manera estructural de conocerlos causalmente. Es decir, para poder ser conocidos por la razón humana, los hechos humanos resultan des-humanizados, des-subjetivados. Pero, justamente por esto, no se presentan (o puede lógicamente pensarse que no se presentan) directamente en su realidad misma, en su "en si" profundo y original, en la espontaneidad activa de su subjetividad, sino que se manifiestan y aparecen con el aspecto que pueden mostrarnos desde nuestra estructural perspectiva racional. Por tanto, los actos humanos pueden no tener esas características deterministas que tienen como "fenómenos", como "objetos de conocimiento", y que deben tener para poder ser conocidos cientificamente por el hombre. Pueden, por ende, no estar sujetos al principio de determinismo causal, que a fin de cuentas no tiene valor absoluto-ontológico sino valor absoluto-fenoménico o, si arriesgadamente se quiere, condicionado, válido bajo las condiciones 
del pensar humano. En breve: el determinismo causal vale sólo para los fenómenos temporales.

Entonces es posible "pensar" (no "conocer") que, por debajo de los actos humanos sociohistóricos que experimentamos y conocemos y fuera del horizonte alcanzable por nuestra mirada racional cientifica, exista un lugar y un espacio por donde fluya la energía espontánea y la exigencia de la libertad innovadora y creadora, el espacio de la moral y de la política, oculto a la mirada del conocimiento científico. Es posible "pensar" que sí haya cabida en el mundo y en la historia para lo incondicionado, para lo no sujeto a condiciones necesarias y suficientes, a causas determinantes: para la libertad. Es posible "pensar" que por debajo de la historia humana fatalista y carcelaria que conocemos y nos angustia, exista en contrapunto "otra" historia, la de "la hazaña de la libertad", la de la autodeterminación, la de la libre iniciativa, la de la voluntad que sólo se mueve por sus fines propios y que puede realizarlos. Es posible "pensar" que exista un "reino de los fines" (Reich der Zwecke), un "mundo inteligible, sobresensible" (intelligible, vernünftige, übersinnliche Welt), que en realidad sostiene y fundamenta por debajo, en su misterio racional, al "reino de los hechos naturales", al "reino de las causas", a la dimensión y secuencia temporal de los fenómenos, al "mundo sensible". Es posible "conocer" (Erkennen) sólo y necesariamente un "reino de causas" ubicado en el nivel de los actos humanos como "objetos" (Gegenstand) de conocimiento científico, pero es posible "pensar" (Denken) postulatoria y no contradictoriamente un "reino de fines", de valores, ubicado en el nivel de los actos humanos como "objetos" (Objekt), en su mismidad real. Es posible "conocer" sólo y necesariamente "la causalidad condicionada", "la causa natural" (Naturursache), pero también es posible "pensar" "la causalidad incondicionada" de esa "causa inteligible" que es "el deber-ser" (Sollen). El conocimiento fenoménico cientifico sólo puede alcanzar limitadamente la causalidad determinista del ser fáctico (Dasein), pero el pensamiento racional congruente puede y debe extenderse hasta la causalidad imperativa del deber-ser moral. Y esta última es la causalidad subterránea y fundamental de la historia auténticamente humana, de la historia ilustrada, moral, y de una historia política rigurosamente centrada en el imperativo moral-jurídico de la libertad universal y absoluta, de "la persona como fin en si". De esta forma, lo que pierde el conocimiento de la razón pura lo recupera el postulado de la razón práctica. $Y$ así como el pensamiento es necesariamente referencia a causas, la nación es la referencia a fines, la referencia al valor en'sf de la libertad.

Esta conclusión kantiana de una doble dimensión de la historia social, la dimensión fenoménica subordinada a causas y la dimensión práctica 
referida a fines establece en verdad la irreductibilidad entre ser y deberser, entre hechos y valores, entre condiciones de acción y sentido de la acción, así como establece la diferenciación radical entre ciencia y política, teoría y práctica. $Y$ es a partir de esta conclusión de Kant que la tradición filosófica y epistemológica alemana comienza a plantearse el problema de la relación entre causalidad y significación, causas y fines, hechos y valores, naturaleza e historia, razón y acción, técnica y práctica, "trabajo" y "acción comunicativa" (Habermas) en la historia social y, en conexión con esto, el problema de la posibilidad de una ciencia de la historia y de la sociedad y de su originalidad epistemológico-metodológica, así como el problema recapitulador de la relación entre ciencia y política. El idealismo alemán, el materialismo histórico, el historicismo, el neokantismo y el weberianismo se plantearon este problema e intentaron resolverlo ora rompiendo con la dicotomía kantiana y poniéndola dialécticamente en movimiento como dos momentos contradictorios de una unidad real, ora renovándola y refinándola para poder dar cabida a la reivindicación de la originalidad y peculiaridad de las ciencias sociohistóricas.

Kant establece, pues, una doble causalidad. Por un lado, la ciencia procede en su ordenamiento conceptual de los fenómenos según un esquema de explicación causal determinista, según leyes de validez incondicional, por lo que su objeto de conocimiento posible es "el reino de las causas" sin significación moral y política, as como la realidad es un producto efectuado necesariamente por causas y los fines de los actores humanos son efectos objetivos necesarios. Por otro lado, la política-moral procede en su ordenamiento práctico de los fenómenos según un esquema de explicación causal teleológica, según fines de valor incondicional, por lo que su objetivo de aspiración y acción posible es "el reino de los fines" sin posibilidad de conocimiento racional; la realidad es un producto de fines libres y los fines de los actores humanos son las reales causas. Kant, pues, establece una doble causalidad, la determinista necesaria y la teleológica libre, la natural fáctica y la social axiológica, la que rige en los hechos del ser y la que quiere regir en los hechos desde el deber-ser del hombre. La primera quiere subordinar a sí misma a la segunda, desacreditándola teóricamente como un factor cuya existencia de ninguna manera se basa en una argumentación racional. La segunda quiere subordinar a sí misma a la primera, desacreditándola prácticamente como un factor cuya existencia reconocida tiene sólo significado en la medida que es puesta al servicio y en función del imperativo moral. Estas dos causalidades que se entrelazan y cruzan en la historia no podrán terminár nunca en la historia anudándose, alineándose, homogeneizándose. Nunca podrán recubrirse recíprocamente y tendrán que correr paralelas 
como dos esquemas alternativos de explicación teórica igualmente válidos de la historia y como dos movimientos de la historia real del hombre.

Pero esta conclusión de una doble causalidad dentro de la historia social afecta severa y negativamente la posibilidad de que la reflexión sobre la sociedad y la historia, sobre la política, se constituya y transforme en ciencia en sentido estricto. Los principios de la acción humana logran evitar caer bajo el determinismo natural, sólo porque quedan fuera de la experiencia y del concepto, fuera de la ciencia. La filosofía crítica parece no tener la capacidad de fundamentar la posibilidad de una ciencia de la historia, una ciencia de la política. Se trata de una alternativa excluyente: o la política es asunto de la libertad y entonces no puede ser científica o la política es asunto de la razón cientifica y entonces no puede ser emancipadora y revolucionaria. Para Kant (y quizá para cualquier político de vocación) sería demasiado caro el precio que la polf́tica pagaría por ser ciencia, en la medida que la "cientifización" de la polf́tica implicarfa renunciar a la idea de que la historia y la sociedad civil sean materia disponible para los fines de la voluntad (moral) del sujeto, abandonar la idea de que el sujeto a la luz del imperativo moral como ius strictum deba y pueda incidir en la realidad, cambiando la faz de la tierra y el curso de la historia, racionalizándolas. En suma, la política como asunto de la voluntad teleológica y la ciencia como asunto de la razón determinista son entre sí independientes y recíprocamente extrañas. La política es en sí la voluntad de los fines, la utopía racional de la racionalización del hombre en la historia como puro incondicional en sí.

Existe una ruptura entre la polftica como objeto de conocimiento y la política como intención, es decir, entre la política como conjunto de hechos y la polftica como conjunto de fines que se entienden alcanzar mediante los hechos. Si estudiamos científicamente los hechos humanos, necesariamente deberán ser concebidos como una sucesión de eventos en los que la libre iniciativa de los actores aparece como una ilusión subjetiva. Si en cambio nos desplazamos con el pensamiento en el nivel de la "realidad en si", podemos sin duda dar sentido a la política como expresión de intenciones, pero no tenemos a disposición un "conocimiento" en sentido estricto, no tenemos la posibilidad de comprobar nuestra hipótesis por medio de la experiencia. La experiencia, condicionada por nuestra manera de pensarla, está totalmente sujeta al principio de la causalidad necesaria.4

Disuelta, por incompatible, la posibilidad de una ciencia racional de la polftica según causas, de una ciencia empírico-explicativa, y aceptada

4 U. Mathieu, Kant, en Storia delle idee politiche, economiche e sociali. Vol. IV, 8, UTET, Torino, 1975, pp. 747-8. 
por otro lado la fundamentación de la política con base en la postulación racional de los fines incondicionales de la voluntad humana, la única posibilidad de "ciencia" de la política resulta ser una ciencia normativa, una ciencia del deber ser político y de los principios absolutos que deben determinar al Estado y a la acción política ciudadana. La ciencia política es, entonces filosofía política y filosofía política moral, cuyo objetivo es determinar a priori, desde la absolutez de la moralidad racional, la juridicidad ideal del Estado y la soberanfa jurídica del Estado y por sobre el Estado. La ciencia politica significa, entonces, moralización y juridificación de la acción estatal y ciudadana, descubrimiento y fundamentación de la absolutez jurídica de la persona humana, gufa ilustrada e ilustradora de la positivación constitucional de ese nuevo y sublime jusnaturalismo apriorísticamente fundado. Para Kant la auténtica ciencia política no es, ni puede, ni debe ser la que sólo describe y explica los hechos políticos o la polf́tica tal como sucede, sino la que atiende y destaca la causalidad propia e irreductible de la acción humana y política, es decir, la causalidad imperativa de los fines. Esta ciencia sólo puede colocarse inevitablemente bajo y dentro de la ley moral racional y debe constituirse como ciencia normativa. Una ciencia al imperativo, no al indicativo. $Y$ esta ciencia política normativa, que tiene firme la ley moral como expresión del fin absolutamente válido de la acción humana, exige que conformemos los hechos humanos, la sociedad civil y la sociedad política, según principios racionales puros de acción e interacción, exige que transformemos los hechos e intereses sociopoliticoeconómicos en instituciones racionales. Pero, en el nivel de conocimiento, no sabemos si esto puede suceder y cómo, sino que al contrario sabemos que esto no puede suceder.

Kant está tan persuadido de la validez de sus resultados que, a sus setenta años, comienza a interesarse en política cuando considera que la Revolución francesa es el primer hecho histórico y el más serio intento jamás sucedido de supeditar los hechos civiles y políticos a los principios de la razón, a la ley moral y jurídica, el intento de dar carne histórica a las exigencias de la razón práctica y de dar realidad a la filosofía: la filosofía era revolucionaria y la revolución era filosófica. Francia era un poco Kant y, mediante la boca y la mente del prudentísimo filósofo, Francia era también un crítica desde Königsberg a la Prusia feudal, así como era de hecho una invitación imperativa a lo que debla ser de acuerdo con la razón.

Si a partir de Kant la filosofía alemana comienza a interesarse en la fundamentación racional de la política, es decir, del Estado moderno y de su correspondiente sociedad civil burguesa, no es tampoco menos cierto que la nueva fundamentación de la nueva política conlleva también, a 
causa de él, la separación de la política respecto de la ciencia empírica, causal, y su vinculación con la filosofía moral, teleológica, normativa: la ciencia política como teoría jurídica del Estado. Las ciencias del hombre empiezan entonces a fundarse por su "referencia a valores", por su referencia a la significación y al "sentido de la acción" del hombre, y empiezan a distanciarse de la causalidad empírica, del origen y desarrollo de los hechos sociales según causas. La causalidad y la significación, las causas y los fines, los hechos y los valores, la naturaleza y la historia humana, la ideología y la utopía se presentan como una alternativa excluyente y dicotómica para la teoría del conocimiento, para la epistemología y la metodología de la ciencia. En Kant se trata de dos dimensiones fijas e irreconciliables, y a partir de él (contra Kant o por Kant) empieza el imponente recorrido de la inteligencia alemana del siglo xIx en su doble tarea de fundamentación de la nueva política y de la nueva ciencia de la historia social. La cuestión política y la cuestión teórica están sin duda vinculadas, aunque pensar la existencia, la naturaleza y el ámbito de su vinculación fue un largo y fatigoso recorrido, aún no terminado, pero en el cual ya existen indicaciones de por dónde no se llega a ningún lado.

En resumen, la distinción que Kant pone entre razón teórica y razón práctica es la raíz de la distinción entre las ciencias de la naturaleza (Naturwissenschaften), que operan según un esquema causal estricto determinista, y las ciencias de la acción humana, de la cultura, del espíritu (Kulturwissenschaften, Geisteswissenschaften), que operan según un esquema de referencia al valor, a la norma moral-jurídica, el deber-ser, y que se estructuran consiguientemente según un esquema causal teleológico. Kant representa el punto de partida de la drástica distinción entre ciencias analítico-hipotéticas y ciencias hermenéuticas, por causas eficientes y por causas finales, explicativas y "comprensivas del sentido". Por consiguiente, de él proviene la distinción entre ciencia y política, a condición de que no se conceptualice la política o el Estado como pura actividad de fuerza y violencia o como una realidad que es mera consecuencia o resonancia de intereses, pulsiones, poderes y condiciones prepolíticos; en este caso, la política caería obviamente bajo el "reino de las causas" y sería entonces objeto de ciencia. Economicismos, contractualismos, vitalismos y leviatanismos pueden sin duda construir una ciencia de la política porque en esta perspectiva la política es causa o efecto de la realidad social empíricamente dada. Pero, por esto, la política deja de ser una actividad libre y conscientemente "humana", decae en "naturaleza" inexorable y predeterminada. Y esta idea de la política la hemos padecido.

La distinción entre la ciencia y la política vale, en cambio, cuando la 
política o el Estado, con sus atributos específicos de poder y coacción, son conceptualizados como "instituciones", como producción humana de sociedad y, por ende, invocan necesariamente la verdad de la razón acerca del hombre en sociedad como su fundamento y principio. Cuando la política no es entendida como mera fuerza de afirmación de intereses y poderes sino como afirmación social e histórica de verdades y valores racionales, la ciencia se distingue y se separa de la política. Pues aquélla explica el ser de los hechos sociales, pero ésta los revoluciona y transforma a fondo, a la luz del deber-ser racional de la sociedad, de acuerdo con el concepto y la norma racional de humanidad.

Pero, por esto mismo, también a Kant es imputable el hecho de que la "ciencia política", imperativa más que indicativa, se haya emparentado estrechamente con el deber-ser de la política y del Estado y, por ende, el hecho de que continuamente la ciencia social asuma como propia la tarea de recomendar, enseñar, amonestar, proponer y hasta predicar lo que deben ser y hacer las asociaciones políticas y la gran asociación estatal. También es imputable al filósofo la idea de que la verdad y el valor de la política y del Estado encuentren su lugar auténtico en los intelectuales más que en los políticos, en los enunciados universales de la ciencia más que en las acciones particulares de la política. Y por último, y con base en las anteriores premisas y supuestos, la convicción de que las ideas y los enunciados científicos estén intrínsecamente llamados a ser o sean efectivamente fuerzas políticas e históricas, de que la razón sea fuerza real y que el deber-ser de las instituciones sociales sea el movimiento y el motor del ser de los hechos sociales y políticos. En suma: la "vocación científica" como "vocación política".

\section{Filosofia, revolución, restauración}

La vida de Hegel (1770-1831) está contrapunteada por la vida de la revolución: la revolución "juiciosa" del 89 , los años del terror, el ascenso de Napoleón, la irradiación de la revolución en Alemania y Europa, las guerras emancipadoras napoleónicas, la derrota, los hechos restauradores del viejo orden. La revolución fue un largo proceso inquietante y bifronte que abría tanto a la esperanza como al miedo, a la esperanza en un mundo ordenado de acuerdo a los principios de razón y libertad, al miedo ante una razón y libertad que violenta e impositivamente ejecutaban su ordenamiento del nuevo mundo: ilustración y terror. Es así que a los años apasionados y radicales del joven Hegel en Tübingen y Berna siguieron los años reflexivos y críticos de Jena y Berlín. El 30 de octubre de 1819 escribe a su amigo Creuzer: "Acabo de cumplir cincuenta años $y$ he pasado treinta de ellos en medio de estos tiempos perpetuamente 
intranquilos del temor y de la esperanza, aunque siempre esperé que algún día desaparecerían. Ahora en cambio debo reconocer que todo esto seguirá su marcha y en las horas tristes tiendo a pensar que cada vez será más duro" (carta 359). De este miedo y esperanza nace y crece la filosofía hegeliana. Su tarea fue entender y darse razón, en profundidad, de la razón revolucionaria, del terror revolucionario, de la contrarrevolución restauradora. Y para Hegel la profundidad de esta tarea se alcanza sólo en el nivel de la dialéctica del sujeto-objeto, del pensar-ser, de la libertad- realidad, del fin significativo-necesidad causal, del espiritu-naturaleza, de la filosofía-historia. Este descubrimiento fue logrado y consolidado progresivamente al calor de la revolución, desde Tübingen hasta Jena y Berlín.

El acontecimiento en el que se concentran todas las determinaciones de la relación entre la filosofía y la historia temporal, y en el que de manera ejemplar se dibujan los problemas de ataque y defensa de la filosofía respecto de la historia temporal es para Hegel la Revolución francesa. Y no hay ninguna otra filosofía que hasta en sus más recónditos impulsos sea en verdad filosofía de la revolución como la filosofía de Hegel.s

Jurgen Habermas añade: Quisiera completar esta tesis de Joachim Ritter con una segunda tesis: para no sacrificar la filosofía al desafío de la revolución, Hegel constituyó la revolución como principio de su filosofía... Hegel festeja la revolución porque la teme. Hegel erige, sí, la revolución como principio de la filosofía, pero en favor de una filosofía que en cuanto tal supere la revolución. La filosofía hegeliana de la revolución es la filosof́a de Hegel como crítica de la revolución. ${ }^{6}$

La esperanza de Hegel en la revolución y su compromiso inalterado con ella a lo largo de su vida radica en el hecho de que por primera vez en la historia, mediante la revolución, la razón y la libertad del hombre se han convertido en el principio constitutivo del ordenamiento sociopolítico. Lo "inaudito históricamente" y lo positivo de la Revolución francesa, pese a sus excesos descorazonadores y atemorizadores, reside en haber constituido al pensamiento en la norma y contenido del mundo social y al hombre consciente y libre en el sujeto social y el sujeto politico, en haber elevado a derecho civil y político la libertad que la filosoffa racional fundamentó como la calidad intrínseca y propia del hombre, como derecho natural y por tanto universal. La revolución es, para Hegel, la esperanza en la realización de la filosofía, es decir, la esperanza 
en la existencia de una concreción sociopolítica para la libertad humana como derecho y cuyo descubrimiento y carácter de derecho universal es producto de la razón filosófica. En la libertad humana como principio constitutivo de lo social y lo político, en la filosofía como principio constituyente de la sociedad civil y política, radica lo originalmente nuevo y propio de la revolución, aś como en ella se basa la esperanza en la revolución como una "nueva época". Por esto Hegel puede entusiasmarse y festejar puntualmente cada año la toma de la Bastilla.

A la luz del pensamiento del derecho... se ha erigido una constitución y se exige que todo se base en este fundamento. Nunca desde que el sol ha estado en el firmamento y los planetas han dado vueltas a su alrededor se había percibido que la existencia del hombre se centra en su cabeza, es decir, en el pensamiento, por cuya inspiración construye el hombre el mundo de la realidad... Hasta ahora el hombre no había llegado a reconocer el principio de que el pensamiento debe gobernar la realidad espiritual. Ésta fue una soberbia aurora del pensamiento. Todos los seres pensantes comparten el júbilo de esta época. Una emo ción sublime se ha apoderado de estos tiempos y el entusiasmo del Espíritu ha estremecido al mundo.?

Pero también la revolución infunde miedo. El temor de Hegel nace de la incapacidad mostrada por la revolución para construir un orden sociopolítico estable y positivo. La teorización hegeliana atribuye directamente esta incapacidad al "ateismo del mundo moral", en que caen tanto los revolucionarios como los actores de la restauración, por promover y ahondar, en su interpretación de la revolución y en su acción política, la ruptura entre la filosofía teórica y el proceso histórico, entre la filosofía y el tiempo. En efecto, si la esperanza se fundamentaba en la vinculación que la revolución proyectaba establecer entre la filosofía y la historia, el miedo - experimentado y padecido en los sombríos años del terror- radica en esa ruptura inmediata y drástica entre la filosofía y la historia, entre la razón y la revolución, que los revolucionarios provocan y agudizan en su acción y que paradójicamente los asemeja y acerca a los reaccionarios. Ambos coinciden en pensar que el tiempo presente de la revolución expresa y realiza la emancipación de la historia social respecto de la tradición filosófica, en cuanto critica y desvaloriza toda fundamentación y construcción de lo social y lo político que pretenda llevarse a cabo con referencia a una filosofía del ser en cuanto ser $y$, por tanto, a lo absoluto y lo divino: "el ateísmo del mundo moral", el ateísmo del mundo de las relaciones humanas, de la nueva historia social y polí-

7 G. W. F. Hegel, Philosophie der Geschichte. Obras completas, vol. XI, Edit. Hoffmeister, Hamburg, 1955, p. 557. 
tica. La razón y la libertad de la ilustración, entronizadas como el principio de reordenamiento de la historia social, son en su raíz antimetafísicas y antiteológicas. Por esto, los hombres de la restauración, que tratan de rescatar la dimensión de lo divino, ante el acoso de la razón revolucionaria, desplazan y ubican a Dios en la subjetividad, en la interioridad de la conciencia moral, en la convicción y la fe, o en la vitalidad, orden y belleza de la naturaleza; con ello reconocen que Dios es externo y ajeno a la historia sociopolítica y que, en particular, el cristianismo ha perdido enteramente su dominio sobre la historia humana, que “el universo más bien debe ser dejado al dominio de la casualidad y del capricho, debe ser abandonado por Dios; de suerte que, según este ateísmo del mundo moral, la verdad se encuentra fuera de él y a la vez, como también debe existir en él una razón, la verdad es únicamente un problema". 8 La ruptura entre filosofia y siempo, ser absoluto e historia, teorfa y práctica, desencadena el monstruoso cortejo de los males y vicios del proceso revolucionario.

Paradójicamente, cercana a la reacción romántica de Schelling, Jacobi, Novalis, es la postura jacobina de los revolucionarios ilustrados, con la única pero tremenda diferencia de que si los románticos terminan en el escapismo resignado e impotente de "la buena conciencia" y de "el alma bella" ante el curso de una realidad social horrenda e inmoral, los jacobinos implantan violentamente en la realidad social misma su "libertad absoluta" mediante "el Terror". ${ }^{9}$ En efecto, los revolucionarios se mueven por el principio de la libertad sin limitación, que por su calidad de principio vale universalmente para todos y cada uno de los individuos libres particulares. No puede existir realidad alguna que oponga condiciones y restricciones al principio. No puede haber siquiera otras libertades que, por su presencia y acción, coarten y limiten el carácter absoluto del ser libre particular, el concepto o proyecto que éste tenga de la realización y organización de la libertad en la sociedad. Para realizar el principio es necesario suprimir efectivamente la expresión y realización de las voluntades particulares. Esta contradicción y autonegación del principio universal de la libertad absoluta particular (libertad formal-subjetiva, añade Hegel con profundidad) se expresa y se realiza concretamente en el terror colectivo y recíproco. La pluralidad de ingenierías constitucionales termina en antagonismo y muerte. El Terror es el resultado lógico del principio de libertad absoluta, si ésta es entendida y ejercida como libertad formal y subjetiva, aún no sustancial y objetiva. Esta conceptualización absoluta y particularista del principio

8 G. W. F. Hegel, Filosofía del Derecho. Ed., UNAM, México, D. F., 1975, p. 6.

๑ G. W. F. Hegel, Fenomenologia del Espiritu. Ed. FCE, México, 1973, p. 343. 
universal de la libertad se revierte en su negación y "sólo le resta el actuar negativo, la furia de la destrucción, el terror".

La única obra y el único acto de la libertad universal es la muerte, pero una muerte que no tiene ninguna riqueza interior y ninguna repleción, pues lo que niega es ese punto incompleto de la libertad absoluta del sí mismo particular; es, por tanto, la muerte más fría y más trivial, sin otra significación que la de cortar una cabeza de col o la de beber un sorbo de agua. En la insulsez de esta frase consiste la sabiduría del gobierno, la realización del entendimiento de la voluntad universal. El gobierno sólo es este punto fijo, es decir, la individualidad de la voluntad universal... Con ello, excluye por una parte a los demás individuos de su obrar y, por otra parte, se constituye como un gobierno dotado de una voluntad determinada y así contrapuesta a la voluntad universal: el gobierno, por tanto, sólo puede presentarse simplemente como una facción. ${ }^{10}$

En esta autodestrucción interminable y en este suicidio colectivo de la revolución se manifiesta trágicamente el ateísmo del mundo social, y en la experiencia del "terror de la muerte se intuye la esencia negativa de la libertad", de aquella que aún no ha llegado a su concepto verda. dero y a su existencia histórica efectiva (lo que es lo mismo). El proyecto jacobino es la furia del concepto abstracto separado de la vida social real, la expresión de una filosofía desgajada de su tiempo y de una teoría que se pretende universal sin recoger dentro de su estructura conceptual la totalidad de lo que concretamente existe.

De acuerdo con el principio de la razón, el resultado filosófico de la ilustración y de su propaganda destructora y superadora de la fe - la cual para Hegel es una "ilustración insatisfecha" - consistió en la afirmación de que el mundo es sólo pensamiento del sujeto racional y voluntad del sujeto libre: el mundo como concepto y como volición de acuerdo con el concepto. Esta afirmación tan gnoseológicamente radical de la subjetividad racional $y$, por ende, tan abstracta, implica necesariamente que la realidad viva, concreta y determinada del mundo sea elaborada y reducida a su concepto abstracto y muerto de esencia, de "esencia pura" y, así, vacía de la riqueza de sus determinaciones particulares efectivamente existentes (la instancia del Historicismo romántico). Y este resultado, al establecer la separación entre razón y mundo, concepto y realidad, conduce necesariamente a que "el concepto absoluto se convierta él mismo en su objeto" y a que "el puro pensamiento sea la pura cosa". El principio de la razón no puede ir más allá del mero concepto de mundo conceptualizado. El concepto racional está

10 Ibidem, p. 347. 
obligado a devorar y borrar la multiplicidad y la diferencia de las cosas y ponerse en lugar de ellas como el objeto de conocimiento. Por esto es demasiado caro el precio que paga la filosofia de la subjetividad racional y libre de la ilustración en su inmediata superación de la fe, pues en la fe la conciencia todavía estaba íntimamente vinculada al "más allá" de la totalidad del ser y por ende al Absoluto, aunque de manera enajenada y vacía, ya que la fe huía también de la riqueza de las determinaciones del mundo y de la historia y estaba obligada a ignorarlas, para poder asir con confianza la totalidad y el Absoluto. El precio de la filosofía ilustrada es la separación entre el pensar y el ser, la filosofía y la historia. El precio del concepto racionalista es la desvinculación y el aislamiento respecto de la riqueza concreta y diferenciada del mundo, particularmente del mundo de la historia social. El mundo natural y social queda entonces opuesto al concepto racional como un "más allá" incognoscible $e$ indisponible en su realidad intrínseca, tan plena de determinaciones originales y vivas.

Es "el más allá absolutamente extraño" para la razón abstracta. El mundo es cognoscible sólo como "puro concepto", "pura esencia indiferenciada". El mundo es disponible sólo para una acción que se ejecute de acuerdo con el concepto que se tiene acerca de él y, por ende, es una acción externa y extraña, que no puede escapar a la fuerza y violencia. Para Hegel, en el fondo, la ilustración - por su crítica a la fe- no es otra cosa que la fe llevada a su verdad real. Por esto mismo, la conciencia enfrenta los mismos problemas de dualidad, vacuidad, extrañamiento, heterogeneidad, aunque ahora los viva y plantee en un nivel rigurosamente racional, conceptual.

El resultado final de la ilustración ha sido oponer mera y puramente la totalidad del mundo sensible, recogida y expresada por el concepto iluminado de la razón humana, a la totalidad trascendente del ser, recogida y expresada por la representación de la fe ciega en Dios. La ilustración, contra el sujeto de la fe desvinculado del mundo, ha opuesto simplemente un sujeto vinculado al mundo, pero su vinculación sucede sólo por su razón conceptualizadora, por sus conceptos puros, genéricos y formales. Sin embargo, la fe y la razón conceptual no dejan de ser actividades y representaciones de una autoconciencia particular que está separada efectivamente del mundo real en su totalidad en toda la amplia y variada riqueza de sus determinaciones. $Y$ dejan escapar de diversa manera en sus representaciones, en la creencia o en el concepto, la multiplicidad, la contingencia y las diferencias concretas y vivas de la naturaleza y de la historia social.

De hecho, la fe ha devenido aquí lo mismo que la ilustración, a sa- 
ber, la conciencia de la relación entre lo finito que es en sí y lo absoluto carente de predicados, desconocido e incognoscible. Sólo que la segunda es la ilustración satisfecha y la primera, la fe, la ilustración insatisfecha. Sin embargo, se pondrá de manifiesto en la misma ilustración si ella puede mantenerse en su satisfacción, pues detrás de ella está agazapado ese anhelo del Espíritu opaco que sufre por la pérdida de su mundo espiritual. La misma ilustración posee dentro de sí esta mácula del anhelo insatisfecho, ya que ella es el objeto puro en su esencia vacía, es la acción y el movimiento para sobrepasar su ser singular e ir hacia el más allá inacabado, es el objeto sólo acabado en su total carencia de utilidad.11

La fe y su objeto, la esencia absoluta, han sido liquidadas. Ahora la ilustración reconquista y reafirma la pluralidad de los seres, reconstituyendo la existencia real de la conciencia particular y de los seres y restableciendo su relación cognoscitiva y práctica. La ilustración retrotrae de nuevo la conciencia hacia el mundo natural y social del que se había escapado y al que había eludido por extraviarse en las representaciones de la fe. De nuevo, la conciencia está mundanizada y referida a las realidades particulares y diferentes del mundo. Sin duda, el énfasis racionalista de la ilustración ocasionó que la relación entre la conciencia y el mundo pasara por la mediación del concepto y que la conciencia estuviera referida al mundo sólo conceptualmente, sólo abstracta y formalmente. Pero, a pesar de ello, el resultado positivo de la ilustración fue la reducción del pensamiento a concepto del mundo y la reducción del mundo a concepto del sujeto. $\mathrm{Y}$ esto desencadenó consecuencias históricas y teóricas muy significativas para la conformación de lá modernidad.

Liquidado el Absoluto, todo se vuelve relativo y cambian los polos de la relación. En efecto, esta recíproca remisión y reducción de la conciencia y del mundo pone y expresa el hecho de que la conciencia y el mundo son intrínsecamente relativos y necesarios el uno para el otro, de que cada uno existe referido al otro y para la realización del otro: la ronciencia, para que el mundo llegue a su concepto y a su apercepción; el mundo, para que la conciencia sea acto de conocimiento y autoconocimiento. En la reconquista de la finitud mundana de la conciencia se pone y manifiesta el principio de "la Utilidad" (die Nützlichkeit), entendido éste como el hecho universal y necesario de que "todo es tanto en sf como para un otro", es decir, todo es "útil", todo es medio y fin. En la utilidad universal, en "el utilizar a los demás y ser utilizado", en ser "miembro de la tropa de la utilidad común y de la utilización universal" radica fundamentalmente "la sabiduría de la ilustración" y su

11 Ibidem, p. 337. 
"verdad". A la totalidad metafísica indiferenciada de la fe se opone ahora la organicidad funcional mundana de la razón. La conciencia transita de la esencia, objeto de contemplación, al mundo, objeto de la práctica, al mismo tiempo que viaja de la Absolutez trasmundana a las relaciones inmanentes entre hombre y mundo. Este descubrimiento de la utilidad universal significa fundamentalmente que todo el mundo real es útil para la conciencia y es utilizable por ella: "La conciencia ha encontrado en la utilidad su concepto."

La disponibilidad funcional del mundo es en un primer momento sólo descubierta y pensada, sólo "objeto de conocimiento" y "fin que la conciencia no posee ya de manera inmediata". La realización efectiva del concepto del mundo como utilidad para el sujeto, la utilización efectiva del mundo como utilidad para el sujeto, la utilización efectiva del mundo, es la acción, la práctica. Y la práctica del hombre puede ser pensada y actuada sólo como "libertad absoluta", dada la total funcionalización del mundo social y natural para el sujeto. "Esta recuperación de la forma de la objetividad de lo útil ya ha acaecido en sí. Y de esta conmoción interior surge la real conmoción de la realidad, la nueva figura de la conciencia, la libertad absoluta." 12

Concepto abstracto, utilización absolutamente libre de la naturaleza y de la sociedad y Terror se remiten intrínsecamente el uno al otro y se desarrollan de manera conjunta e interdependiente. La conceptualización de la razón ilustrada pierde al mundo en su verdad efectiva, pero lo gana en su utilidad: lo pierde como verdadero pero lo gana como útil. Para la conciencia hacedora de conceptos abstractos la única posible verdad del mundo es su utilizabilidad y utilidad, su carácter de materia totalmente subordinada y funcionalmente disponible para la conciencia. Y ésta fue la conclusión de Kant. Por esto la conciencia nace y se levanta como "libertad absoluta". Su "nueva figura" es la práctica incondicional e ilimitada, la reconquista egocéntrica del mundo objetivo social y natural, su posesión y dominio: economía política y jusnaturalismo, burgués y ciudadano, liberalismo económico y político, Capital y República. Si la realidad socionatural resulta definitivamente perdida desde el punto de vista conceptual abstracto de la ilustración, pero fundadamente recuperable con base en el principio de su naturaleza utilizable, se sigue que la recuperación de la realidad sólo puede suceder como una asimilación violenta del objeto por parte del sujeto, como coerción ilustrada. En efecto, el acercamiento de la conciencia al mando con base en su utilidad es simultáneamente obstaculizado y empujado hacia atrás por ser un acercamiento con base en el concepto. $Y$ éste, a

12 Ibidem, p. 343. 
causa de su estructural extrañamiento de la realidad y por tanto de su impotencia ante ella, termina coherentemente en el Terror. La utilización del mundo orientada por el concepto remata lógicamente en coacción violenta de la sociedad. La universalidad e incondicionalidad del concepto, cuando se yergue como principio orientador de la acción ilustrada utilizadora del mundo, sólo puede cancelar y borrar con puntualidad implacable e incesante las realidades concretas que necesariamente están limitadas por su particularidad y sus condicionamientos y que, por ende, no pueden existir de acuerdo con su puro concepto.

La revolución del concepto, la revolución ilustrada, que en la utilización transformadora del mundo actúa sólo en nombre y con el encargo de los conceptos del sujeto racional, termina congruentemente en la destrucción sistemática e inevitable de toda realidad social que no exista conforme al concepto puro de la razón y no sea disponible a la libertad absoluta del sujeto particular. Es así que el deber ser de la realidad social, establecido a la luz del purísimo concepto del hombre como sujeto racional y libre, termina por borrar violentamente realidades sociales formadas por sujetos y comunidades libres, que a través de su historia material y espiritual han ido configurando sus conceptos de libertad social y de sociedad libre y normando sus prácticas. El concepto de libertad absoluta y pura liquida las libertades reales comunitarias y personales, gestadas en el seno de la historia.

El imperativo kantiano de hacer coincidir concepto y realidad, deber ser y ser, valor y hecho, libertad y sociedad, pudo evitar caer en la desaforada destrucción efectiva del mundo social, porque por debajo de la ilustración de la crítica de la razón pura se coló subrepticiamente el postulado de la razón práctica, que es justamente la manera culta y esclarecida de conservar todavía la fe religiosa de un "más allä", en un "reino espiritual" donde ser y pensar, deber ser y ser, valor y hecho, sólo pueden identificarse cabalmente. La fe transformada en postulado de una identidad metahistórica y metasocial conlleva el reconocimiento racional de la imposibilidad que en la historia social pueda haber identidad entre concepto y realidad, libertad y sociedad. Y, por tanto, implica y advierte la inutilidad de una acción revolucionaria ilustrada que pretenda dar un paso más y pasar de la moral racional y racionalizadora a la política práctica, o que, reivindicando la obligación moral de actuar sólo de acuerdo al imperativo y su postulado, se transforme en poder político, en la voluntad política de realizarlo efectivamente en la sociedad, a cualquier precio. Pero en la ilustración política pura y radical de Robespierre ese imperativo-postulado, ya sin las adherencias moralistas de la fe desechada, origina y despliega la masacre.

Para Hegel, los restauradores y los revolucionarios están de acuerdo, 
sin saberlo, en aceptar el resultado ilustrado de la separación tajante entre sujeto y objeto, conciencia y totalidad efectiva, concepto e historia, aunque los primeros juzguen a la revolución como un hecho trágico y los segundos como un hecho heroico. Los restauradores piensan que, si la realidad social revolucionada debe llevar sola y excusivamente en la arquitectura de su nuevo ordenamiento las marcas violentas del sujeto humano y de su concepto, entonces la realidad auténtica, las marcas del ser total, del Absoluto, de Dios, pueden encontrarse sólo fuera de la realidad social y política, sólo en el corazón, en la vida del alma, en la buena conciencia, en el "alma bella", o bien en el fondo misterioso y palpitante de la naturaleza perfectamente ordenada; por ende, sólo en regiones de vida que son originalmente extrañas al concepto y únicamente revelables al sentimiento, a la fe, a la intuición, a la vivencia. Dios habita en el corazón del hombre y en el pulso de la naturaleza, no en el foro público ni en la historia política.

Para los revolucionarios, en cambio, sólo debe haber un mundo social exclusivamente humano, estructurado de acuerdo con el concepto rigurosamente racional de hombre y, por ende, del concepto de libertad plena, por lo que con coherencia se arrasa con lo prehumano y lo servil, con lo oscuro, lo irracional y lo recibido pasivamente por tradición, así como se destruye toda propuesta o acción que no tenga cabida dentro de la pureza del concepto, mejor dicho, que no tenga cabida dentro del concepto que cada autoconciencia particular con igual derecho tiene de la libertad y de su organización y ámbito de acción en el mundo natural y social. Es así que la restauración, para salvar la realidad substancial y el Absoluto, perdidos a los ojos de la razón de la cultura esclarecida, retrotrae mundo, hombre y Dios a la interioridad de la piedad devota, abandonando la política y la historia social a su destino de "caos y capricho". La revolución, en cambio, para recuperar la realidad perdida, invade atropelladamente el mundo con la intención de conquistarlo conforme a su concepto e implanta el terror en la política y la historia social. Para rescatar las libertades conforme al concepto racional de libertad, las homogeniza coactivamente o las liquida política y físicamente, como indignas de existir.

La restauración prefiere la introversión piadosa del sujeto hacia sí mismo. La revolución elige la extroversión terrorista del sujeto hacia fuera de sí mismo. A su manera, ambas reconocen y registran el fracaso que ante la realidad histórica padece trágicamente el concepto abstracto, el "puro concepto de esencia" de la conciencia. Ambos reconocen el fracaso político de la revolución basada en el concepto ilustrado y, sin embargo, quedan prisioneras en la cárcel de la razón pura conceptualizadora y de los conceptos de la razón pura o en la cárcel de la intimidad nostálgica 
y agresivamente bélica de la autoconciencia particular. El precio de la era del concepto, la ilustración, es el ateísmo del mundo social, la política abandonada al caos, al capricho o al terror. Todo concepto que se ha vuel to externo a la realidad, vacío de determinaciones concretas, es decir, toda separación entre filosofía e historia, paga el precio de un voluntarismo radical en política. La Ilustración muestra y cristaliza con toda claridad la vinculación paradójica que existe entre el racionalismo de la autoconciencia y el irracionalismo de la acción, entre razón ilustrada y sinrazón política, entre el derecho natural abstracto y la vida social. En suma, restauración y revolución terminan respectivamente en el voluntarismo del ensueño escapista o en el voluntarismo de la realización coactiva. Novalis en la poetización romántica de la Edad Media comunitaria, "en aquellos hermosos y esplendorosos tiempos, cuando Europa era una tierra cristiana". Robespierre cortando cabezas con su furia jusnaturalista de destrucción. Ambos radicales y voluntaristas, porque la vida social escapaba al concepto y la historia evadía la teoría.

\section{El proyecto teórico-politico de $\mathrm{Hegel}$}

Desde esta crítica atinadísima a la Ilustración y a la Restauración, Hegel comenzó su inolvidable construcción del pensamiento (la dialéctica del "derecho" hacia el "ethos"). En el nivel teórico esto significó para Hegel preñar de determinaciones históricas particulares a la concepción abstracta universal, así como elevar la historia particular y singular al rango de concepto racional, la historia que el romanticismo había reivindicado y reconquistado, pero que, en su autodefensa y oposición al orgulloso dictado del concepto genérico y formal de "naturaleza humana", decayó en las representaciones irracionales de la fe, la vivencia (Erlebnis), el sentimiento (Einfühlung). Hegel trató de llenar de historia real al mero concepto formal y dar concepto verdadero a la historia meramente sucedida, de lograr la identidad entre lo racional y lo real, entre "lógica" y "fenomenología", de lograr el Concepto (Begriff) como sintesis de verdad e historia, de lo universal y lo particular, de determinismo y teleología, del ser y el deber-ser.

En el nivel práctico-político, esto significó para Hegel llenar el proyecto racional jusnaturalista de la ilustración revolucionaria con la densidad concreta de las conciencias individuales y de las instituciones sociales y políticas tradicionales, que habían sido producidas a lo largo de la historia por comunidades, generaciones, pueblos y naciones, como lo exigían románticos, restauradores y germanistas. Se trataba, en primer lugar, de dar ordenamiento institucional objetivo, comunitario y societal -y ordenamiento de acuerdo con la verdad de razón- a los intentos 
subjetivos que los individuos habían debido llevar a cabo para poder salvarse a sí mismos, para poder salvar su fe, su tradición, su libertad y su autoconciencia personal, ante la embestida de un "derecho natural" genérico e impersonal que había sido erigido como la única norma verdadera de la vida social y de las relaciones sociales. Estos intentos habían conducido a los individuos a refugiarse en la interioridad de la "moralidad", en la intimidad de la autodeterminación de lo que es la idea del Bien y del Deber y, más aún, a constituir la moral como el principio verdadero e irrenunciable de su conducta dentro de las instituciones sociales y políticas (modernas) establecidas sólo jurídicamente y, por esto mismo, soportadas como un mal o un peligro para la moral personal. En segundo lugar, se trataba de dar ordenamiento objetivo, de acuerdo con la verdad de razón, a todas las instituciones sociales y políticas que regían las comunidades regionales y locales y a las corporaciones sociales; instituciones que habían sido producidas a lo largo de una historia propia y viva, y que expresaban y concentraban la energía espontánea y creativa de pueblos y naciones, "el espíritu del pueblo".

En la dimensión práctico-política, Hegel buscaba superar la norma abstracta jusnaturalista del "Estado de Derecho", que sólo recogía y sancionaba la expresión más limitada, subjetiva y formal de la libertad, la que se despliega en la propiedad y el mercado de bienes. Y de superarla, negándola, mediante las instancias de la moralidad individual y de las instituciones sociales de comunicación interpersonal, producidas a lo largo de la historia social. De esta manera, Hegel llevaba el Estado jurídico a la verdad concreta e histórica, sustancial y objetiva, de la libertad individual interior y de las libertades comunitarias, al "Estado Ético". Hegel intentó de esta manera reconciliar en la identidad y en la totalidad orgánica del Estado, la Ilustración y la Restauración, la modernidad y la tradición, el derecho general y la moralidad personal, el derecho natural racional y las instituciones históricas nacionales, las libertades de la naturaleza humana y las libertades comunitarias y corporativas, la República y el Reich.

Estas dos tareas, la teórica y la histórica-política, fueron consumadas inolvidablemente en la construcción hegeliana. Baste aquí someramente recordarlas. Su meta crítica a la crítica kantiana se basa en "la autorreflexión fenomenológica del espíritu", en una "conciencia (que) reflexivamente puede hacer transparente sólo su conexión genética" y su proceso de formación, en una "experiencia fenomenológica de la que resulta el punto de vista del saber absoluto de manera inmanente y necesaria". ${ }^{13}$ En el movimiento espontáneo y reflexivo de la conciencia se pone y se

13 J. Habermas, Erkenntnis und Interesse. Ed. Suhrkamp, Frankfurt am Main, 1969, pp. 16 y 18. 
descubre con toda claridad la distinción entre "entendimiento" (Verstand) y "razón" (Vernunft), así como la orientación y desplazamiento (espontáneo y reflexivo) del entendimiento hacia la razón. ${ }^{14}$

El entendimiento es la razón ligada en su operación a la "certeza sensible", por ende, a la multiplicidad, diferencia, limitación, separación y contingencia de los datos del mundo que caen bajo la experiencia inmediata y que constituyen su materia. Por esto, la formación del concepto, correspondiente al entendimiento, termina en el concepto abstracto, en la conceptualización del mundo natural y social como mera masa de entidades diferentes y separadas, como mera suma de elementos limitados o finitos. Aquí, "el pensamiento, como entendimiento, se cierra en la determinación rígida y en la diferencia de una determinación respecto de las otras; tal producto abstracto y limitado vale para el entendimiento como existente y subsistente en si". Pero este resultado del concepto abstracto analítico, que sólo reproduce y contiene determinaciones finitas e independientes entre sí, es devorado por la misma dialéctica reflexiva de la conciencia. La segmentación y pulverización analítica de la realidad descubre la precariedad y contradicción de su representación conceptual. Ninguno de los elementos simples, aislados e independientes que son conceptualizados, puede ser completamente pensado y entendido sin que la conciencia salga de él y lo trascienda, sin que simultáneamente los relacione a sus opuestos e incluya en su concepto la referencia al opuesto, sin negarlo en su simpleza, clausura y separación. En efecto, nada particular puede ser definido y delimitado conceptualmente de manera univoca sin extrovertirlo, sin hacer de nuevo y necesariamente referencia a lo que la cerrazón del concepto analítico trató de separar y negar, excluir y expulsar. ¿Se puede definir conceptualmente "algo" sin definirlo negativamente, sin oponerlo a los otros, sin negar a los demás, sin constituir a éstos como sus negativos y a su vez como los negadores del contenido cerrado e idéntico del concepto de "algo" y, por esto, negadores de la validez cognoscitiva de este tipo de concepto?

En el mismo acto de la definición y del deslinde, la conciencia advierte que la supuesta identidad exclusiva de su concepto abstracto de lo particular incluye y recupera también dentro de sí todo el universo de lo excluido, de sus contradictorios y opuestos. La conciencia descubre intimamente que la identidad de su contenido lógico lleva en su interior con la mismidad de lo representado también su diferencia y con la igualdad unitaria su oposición. Toda definición de una determinación finita conlleva e incluye de manera intrínseca y necesaria la referencia a lo que

14 Remito a los conocidos párrafos 79, 80, 81 y 82 de G. W. Hegel, Enciclopedia de las Ciencias Filosóficas. Una traducción disponible es la de Ed. Porrúa, pp. 51-52, 4a. edición, México, 1980. 
separó, expulsó y negó, a su negación. De esta manera, se toma conciencia de la necesaria presencia de lo negativo en el concepto "positivo", asf como se advierte que la conexión y el conjunto (sintesis) total penetra al concepto analítico particular y simple. La totalidad habita en el concepto analítico de manera negativa y negadora; y este descubrimiento obliga a la conciencia a autocriticarse y rehacerse, a renovarse y a reproducir sus conceptos, a superarse y desarrollar su verdad y realidad.

En un primer momento, en el momento "dialéctico o negativo racional", la conquista del concepto "intelectual" o "accesible al entendimiento" (verständige Seite) se manifiesta efímera y contradictoria consigo misma: "es el suprimirse por sí mismas de dichas determinaciones finitas y su paso a las opuestas". "La dialéctica es esta resolución inmanente en la cual la unilateralidad y limitación de las determinaciones del entendimiento se expresa como lo que ella es, es decir, como su negación: todo finito tiene la propiedad de suprimirse a sí mismo." Por ello, el concepto analítico y abstracto de lo finito se suprime y sabe que no puede más que suprimirse, que no hay dentro de él contenido positivo e idéntico, siempre igual a sí mismo, fijo, resolutorio y conclusivo, de una vez por todas. El concepto analítico está condenado a captar la contradicción en su identidad, la oposición en su igualdad, la apertura a la totalidad en su cerrazón simple y parcial. Esto significa que la conciencia reconoce la falsedad de su concepto producido y, por ende, se pone (espontánea y reflexivamente) en movimiento a la búsqueda de su verdad e identidad efectiva.

Después, en el "momento especulativo o positivo racional" (vernünftige Seite), la conciencia produce un concepto que sabe que, "aun siendo algo pensado y abstracto, es a la vez algo concreto, porque no es unidad simple y formal, sino unidad de determinaciones diversas; por esto, la filosofía no tiene nada que hacer con meras abstracciones o con pensamientos formales, sino sólo con pensamientos concretos". La conciencia es sacudida y puesta en crisis por la revelación de todo el conjunto de negaciones que cerca y penetra al supuesto concepto cerrado de identidad de lo particular o elemental. Y el resultado relativamente final al que ella llega es, entonces, un concepto de "totalidad determinada", de con-junto o "sin-tesis" de determinaciones diversas. La importancia cognoscitiva del concepto analítico llevó de la mano a la fecundidad teórica del concepto sintético, así como la contradicción intrínseca del concepto abstracto monadista condujo a la fuerza representativa del concepto concreto. Este concepto presenta a la conciencia el "algo" como punto de con-creción o con-junción de muchas realidades y relaciones y, al mismo tiempo, como momento y elemento particular de una totalidad estructural más amplia y en movimiento, en la que está incorporado, sub- 
sumido, integrado. En cada "algo" se expresa una totalidad superior que lo contiene como una de sus determinaciones y cada "algo" es, a su vez, un todo que recoge en sí otras determinaciones y relaciones. La derrota cognoscitiva del elemento simple y separado llevó a concebir el todo complejo, así como el fracaso del "entendimiento", que reproduce al mundo como acervo o suma de entidades aisladas, dio paso a la formación del concepto verdadero de la "razón", que representa al mundo como un universo orgánico dotado de una "conexión inmanente". Es sabido por todos que la totalidad concreta última y verdadera, la que concentra dentro de sí todas las determinaciones existidas, existentes y posibles, es la sustancia absoluta y entera que se sabe sujeto absoluto: el Espíritu.

Pero la dialéctica de la producción de la conciencia no sólo lleva del análisis a la síntesis, del elemento abstracto a la totalidad concreta. La dialéctica de la conciencia nos hace pasar también del determinismo (mecanicista) a la teleologia, de una concepción del mundo como "naturaleza" a un mundo como "espiritu":

el espiritu tiene para nosotros la naturaleza como su presupuesto, de la que él es su verdad y, por tanto, su primer absoluto. En esta verdad, la naturaleza ha desaparecido y el espíritu resulta como la idea que ha llegado a su ser para sí, cuyo objeto y sujeto a la vez es el concepto. ${ }^{15}$

En el nivel del entendimiento, el mundo es sólo "natural", un conjunto plural y diferenciado de esencias o naturalezas, dentro del cual se ubica la "naturaleza humana". Si este conjunto diferenciado se constituye y transfigura en un universo, en "la Naturaleza", esto se debe de nuevo a que la dinámica interna de la lógica formal y su cortejo de conceptos abstractos llega en ella a su máxima y universal abstracción: "la Naturaleza" es el concepto super abstracto que en su comprensión lógica, totalmente vacía y formalizada, recoge toda la extensión lógica de las naturalezas, tanto la humana como las especies animales, vegetales y los cuerpos físicos. Más aún, si este conjunto diferenciado se constituye y transfigura en el universo de la naturaleza, esto se debe no sólo a las conexiones taxonómicas que establece rigurosamente la catalogación lógica del entendimiento, sino sobre todo a las conexiones causales, a las "leyes" que él pone desde su estructural y limitada perspectiva de conocimiento, ligada a la experiencia y al experimento sensible. Para el entendimiento la única manera de dar "conexión" a un mundo, que él representa analítica y abstractamente como conjunto de entidades entre sí separadas

15 Ibidem, § 381 . 
y diferentes, puede suceder sólo mediante leyes de causalidad, leyes de descomposición y composición, de origen y cambio. La perspectiva del concepto universal abstracto de género y especie y la del concepto analítico de elemento prescinden de la riqueza cualitativa y de la totalidad de determinaciones de los individuos concretamente existentes y actuantes. Por ello su única posible manera de pensar la unidad y "conexión inmanente" de la naturaleza sucede mediante leyes generales y genéricas, numéricas y parcializantes. La constitución de un universo natural es sólo posible por la instauración de un "mecanismo universal".

Sin embargo, a la luz del concepto de la razón se niega y supera este esquema causal determinista de leyes universales del entendimiento científico que deposita y expresa en ellas la estructura y el ordenamiento fundamental de la realidad y de su movimiento. En el concepto de la razón, el esquema causal determinista se lleva a su verdad profunda, a la verdad del esquema causal teleológico, por el que se descubre y pone en la historia la autoconciencia y la libertad sustancial y objetiva del espíritu humano y, con él, la del Espíritu Absoluto (no la vacía conciencia y libertad formal y subjetiva del jusnaturalismo ilustrado). El esquema causal determinista reconoce que es sólo la representación y explicación de la naturaleza de la historia social en cuanto "aparecen" al entendimiento y a su concepto abstracto. Aquí la causalidad sabe que es sólo el ordenamiento de la realidad en cuanto "objeto de conocimiento" (no como objeto real y conocimiento real), en cuanto "Gegen-stand", "Dasein", "Erscheinung", es decir, en cuanto realidad que está y aparece ahí delante y se pone enfrente de los sentidos en la obviedad de la pluralidad y contingencia de sus determinaciones y que constituye la materia experimental sobre la que, desde afuera, se elabora el contenido lógico del concepto analítico y del enunciado de la ley, que son indudablemente el primer esfuerzo de la conciencia intelectual por dar unidad y necesidad a las determinaciones sueltas y contingentes de los fenómenos.

Pero Ia reflexión de la conciencia sobre el entendimiento científico hace que éste sepa su determinación y contradicción, que reconozca su saber limitado y su no saber y se desplace así en búsqueda de un nuevo saber resolutorio. Un saber que no sea abstracto y separado del mundo natural y de la historia social, sino interiorizado y entrañado en ellos, un saber idéntico con la realidad y en el que la realidad se manifieste en su mismidad como idéntica con la conciencia y la autoconciencia absoluta: como Espíritu. Aquí, en este punto de llegada del recorrido fenomenológico (que es en sí el punto de partida de la lógica-ontología), en el concepto de la Razón, la naturaleza y la historia se muestran intimamente penetradas por la intencionalidad y por el "sentido" del Espíritu absoluto que las pone en ser, las mueve, encamina y dirige en 
función de sí mismo, para su fin de autorrealización y autoconocimiento completo. Al ojo de la con-ciencia, que no de la ciencia, la realidad natural e histórica se manifiesta movida por una causalidad teleológica necesaria y se desvela como una pancósmica "conexión de sentido" (Zinnzusammenhang), dotada de estructura y ordenamiento teleológico, en tanto que producto libre de un Sujeto Absoluto.

Las leyes causales del entendimiento científico, en la medida que cancelaban y superaban la multiplicidad y la contingencia de las determinaciones de la experiencia sensible (naturaleza e historia), llevándolas. así a su unidad universal y necesaria, fueron sólo el primer y provisional barrunto y anuncio de la verdadera unidad universal y necesaria que funda, sostiene y estructura naturaleza e historia, a saber, la intencionalidad teleológica del Espíritu Absoluto. La realidad entera se revela, entonces, como una estructura llena de sentido, como "significación". Por la dinámica espontánea y reflexiva de la conciencia, sucede el tránsito de la causalidad universal y necesaria, propia del entendimiento analítico-hipotético y separado de la realidad, a la teleología universal y necesaria, sólo accesible a la razón y en la que se sabe que sucede la identidad entre ser y pensar, en la que se sabe que el ser es autoconciencia $\mathrm{y}$, por ende, intencionalidad y finalidad. Hay, pues, un desplazamiento de la explicación por causas a la comprensión por fines, a "la comprensión del sentido" (el "Sinnverständis" weberiano). Dicho de otra manera, la "ex-plicación", que etimológica y lógicamente denota "desplegar algo desde afuera" (el conocimiento del despliegue o desarrollo de la realidad desde el afuera del concepto abstracto y de sus leyes causales), se desplaza a la "com-prensión" que etimológica y lógicamente denota "tomar algo por estar ya con o junto con él", es decir, el conocimiento del despliegue o desarrollo de la realidad como despliegue de la autoconciencia, del Espíritu. A este punto, la causalidad se rebasa en teleologia y en ella llega a su verdad, así como la ciencia natural e histórica asciende y llega a su verdad en filosofia de la Historia: la ciencia se supera en sabiduría (Wissenschaft).

Si volvemos un momento la mirada a Kant, se recordará que en él quedaban separadas ciencia causal y libre conciencia teleológica moral. La teleología de la conciencia humana en el mundo natural e histórico no podía demostrarse teóricamente en su verdad, sino sólo postularse necesaria y universalmente. En este sentido, fluian dentro de la historia humana dos historias gobernadas por dos causalidades: la del "reino de las causas", determinista y demostrada racionalmente, propia del "mundo de experiencia", por un lado; y la del "reino de los fines", autodeterminante e indemostrada racionalmente, propia del "mundo inteligible", por el otro. Se recordará también que esta dualidad entre determinismo 
teórico y teleologismo práctico llevó a una tajante separación entre ciencia y política, razón por la cual el único conocimiento posible de la política era el de una ciencia normativa, de una philosophia practica. Este resultado kantiano queda ahora rebasado por la metacrítica dialéctica de Hegel a la crítica trascendental. Causalidad y teleologia, teoría científica y conciencia moral, ser y deber-ser, razón pura y razón práctica, son removidos de su dura dualidad y de su irreconciliable oposición y son tematizados como momentos necesarios de la formación real de la conciencia, de la formación de la verdad teórica y de la naturaleza humana libre. El postulado encuentra, entonces, su fundación y verdad teórica más allá de la ciencia, así como la ciencia encuentra su verdad más allá de ella misma, en la autoconciencia del Absoluto, y de la misma manera que el determinismo causal se vuelca y se transforma en teleología necésaria. No hay dos historias de la razón o de la conciencia que en este mundo queden paralelas e irredentas, por lo que su unidad deba postularse fideistamente, a la manera de Kant, en una vida trascendente y feliz de las almas inmortales. Hay una sola historia de la conciencia, pero que necesita transitar y elevarse de la ley a la autoconciencia, de la necesidad mundana a la autodeterminación de la libertad, de la naturaleza a la historia, del mundo condicionado al Absoluto que está en acción dentro del mundo.

Este tránsito espontáneo y reflexivo, que acontece al compás de negaciones inseparadas pero incontenibles, es justamente el descubrimiento y la inauguración de la historia, la comprensión de que la realidad no es naturaleza, sino profunda y fundamentalmente historia, historia de la autoconciencia y, por ende, autodeterminación de la libertad y, por consiguiente, realización de sus fines, teleología ética, Ethos. El jusnaturalismo y la economía política, cuyo programa teórico y político se basa en el concepto de "naturaleza humana", se cimbran y derrumban por la fuerza de la historia de la conciencia y de la libertad, que proyecta sus fines y valores y los persigue con el afán de la acción y la dura elección entre alternativas y opciones.

En este sentido, tampoco la ciencia está reñida con la política y separada de ella. Tal distanciamiento es sólo posible para la ilustración, para una teoría separada de la vida y de la acción de la conciencia y de su autodeterminación, que son los reales factores de la historia social. Esto es sólo posible para una teoría que con enunciados y postulados abstractos quiere domeñar con terror el ritmo de la sociedad y quiere determinar, desde el afuera del concepto filosófico o científico, el deberser de los hechos sociales producidos y en proceso. Para una teoría que, asida al vacío concepto de "naturaleza humana" y de sus libertades connaturales formales y subjetivas, quiere marcar y parar la historia 
social civil y política efectiva, la que en su movimiento ha producido y produce las libertades reales, las reconocidas socialmente de manera espontánea y sentida, y las instituciones civiles y políticas que definen el ejercicio objetivo de las libertades.

Pero tal distanciamiento es impensable e inválido para un conocimiento que sabe y reconoce que sólo por dentro y a través de los hechos sociales en movimiento, mediante el desgarramiento asumido de las negociaciones y de los conflictos, se forma el conocimiento verdadero y la verdadera realidad, la teoría real y la realidad de acuerdo con la teoría, la razón teórica y la práctica racional. Para este nivel de conocimiento, el Estado y la política son, en cambio, la consumación de la verdad racional, sustancial y objetiva de aquellas libertades universales que el jusnaturalismo y la economía política habian conceptualizado y realizado de manera meramente formal y subjetiva, contradictoria, así como la consumación de las libertades e instituciones particulares, que la tradición histórica de sociedades y asociaciones interpersonales ha producido y desarrollado. En este sentido, la política y el Estado son la consumación de la autoconciencia y de la autodeterminación, llegadas a su verdad racional y a su realidad verdadera: "Io racional en sf y para si". Si la ciencia empírica se rebasa y transforma en fenomenologia y lógica del Espíritu, en "ciencia de la lógica" (Wissenschaft der Logik), verá en el Estado y en la política el lugar donde el Logos (la autoconciencia y la libertad) se encarna en la historia temporal, el lugar donde la verdad "racional" (sustancial y objetiva) de la autoconciencia y de la autodeterminación tiene cuerpo y suelo histórico y donde la historia sociopolítica alcanza la forma del espíritu verdadero, pues "el Estado es espíritu objetivo", "Espíritu ético en cuanto voluntad patente, clara para sí misma, sustancial, que se piensa y se sabe, que cumple lo que sabe y como lo sabe", y porque en el Estado el individuo "tiene su libertad sustancial, como su esencia, fin y producto de su actividad". Bastaría, cuando menos, releer desprejuicidamente el famoso Prefacio de la Filosofía del Derecho para entender en toda su riqueza la identidad entre saber y política.

Sin embargo, el inolvidable esfuerzo hegeliano se logró sólo por medio y en el nivel de la filosofía, de la ontología. Si Hegel logra englobar el concepto abstracto en el "universal concreto", la causalidad mecánica en la teleologia libre, la postulación moral en la verdad histórica, la teoría en la política, es porque en el fondo engloba la ciencia de la naturaleza y de la sociedad en la Filosofía de la Historia, en la ontología del Espíritu Absoluto como la sustancia y el sujeto de la naturaleza y de la historia social humana. Sin duda, en Hegel se redimen la tradición y la modernidad, la fe religiosa y la ilustración laica y racionalista, 
la revolución y la restauración, el derecho racional y las instituciones éticas populares, pero se redimen en el nivel de filosofía de la historia. Con esto no se quiere sugerir la falsedad de la filosofía ni sugerir que, para ajustar definitivamente cuentas con Hegel y con la filosofía sin más, baste la vulgar invocación de un premoderno argumento de autoridad, a saber, el pronunciamiento de Marx sobre "la miseria de la filosofía" y "la ideología alemana" irredenta. Se quiere sólo destacar que la posible utilización y fecundidad de un esquema causal teleológico y, por consiguiente, una metodologia hermenéutica comprensiva en el conocimiento de la historia social, fue en el caso de Hegel sólo posible en el nivel de filosofía de la historia y no en el de la ciencia histórica y social. De igual manera, es importante hacer notar que se logró la identidad y unidad entre razón y práctica, teoría y política, el saber y el poder, porque Hegel mostró en la dialéctica de la formación de la conciencia verdadera y de la historia social cómo se llegaba necesariamente a un punto de conjunción entre Filosofía y Estado, a pesar de los posteriores remordimientos y denuestos de la izquierda hegeliana. De todos modos, en Hegel, la identidad de la Filosofía como "buho de Minerva", post festum, "después que la realidad ha cumplido su proceso de formación y está realizada".

\section{Algunos problemas heredados por Kant y Hegel a la inteligencia alemana}

Si, a pesar de la pretensión del encabezado, queremos selectivamente enlistar algunos de los problemas que las soluciones de Kant y Hegel heredan a los filósofos e historiadores alemanes y que, en gran parte, hipotecan su manera de pensar la sociedad y la historia social, éstos podrían ser quizá los problemas que se centran en el tema de "la revolución racional", tema que incluye el asunto de la articulación entre la modernidad y la tradición, la razón y la política, la lógica y la historia, los intelectuales y el poder, la ilustración y el historicismo de la restauración. Si se considera firmemente y sin dudas que el principio de la modernidad es reconducir la realidad social, empastada de contrapuestos intereses y poderes de hecho, a instituciones racionales, a la fuerza normativa de la razón, surge entonces toda una constelación de cuestiones. Por ejemplo, la cuestión de si la instancia de la racionalización global de la sociedad sea un descubrimiento y un reclamo que son propios sólo de una tradición cultural, la de la cultura greco-judio-cristiana, la de la cultura de occidente o germánica, y que sólo al interior de esta cultura son válidas y productivas, o bien, dado que la racionalización se basa en el concepto de "naturaleza humana" (como lo ponen de relie- 
ve la filosofía jusnaturalista y la economía política), si la racionalización sea un programa teórico y práctico que toda sociedad está implícita y potencialmente dispuesta a descubrir y reivindicar, o que toda sociedad, en cuanto asociación humana, independientemente de su cultura, debe asumir y realizar incondicionalmente. Dicho de otro modo: las instituciones sociales y políticas racionales de la modernidad, en concreto el Capital y la República, ¿son de facto el resultado más avanzado de la historia social de occidente o deben ser de jure, so pena la barbarie, el proyecto de toda sociedad humana? La revolución tes un proyecto ecuménico obligatorio o un proyecto sólo nacional o regional, diferenciado y condicionado culturalmente?

En conexión con esto, la revolución racional pretende establecer una articulación entre la razón y la historia. Es por ello que hay que preguntarse radicalmente acerca del concepto que se tiene de la razón, de la historia y de su recíproca articulación. Esto implica, de entrada, revisar críticamente y producir alternativamente teorias del conocimiento: gnoseología trascendental, dialéctica, fenomenológica, materialista-histórica, historicista, neokantiana... y, sobre todo, pronunciarse sobre la validez de la ciencia y de la filosofía, asi como sobre sus alcances y límites, sobre su ámbito de conocimiento posible y seguro. En particular, significa a'rontar también la cuestión epistemológica y metodológica acerca del status de verdad de ese conjunto de ciencias nacientes e inciertas que fueron las ciencias históricas y sociales. Por tanto, hay que afrontar la cuestión fundamental acerca de la formación del "concepto histórico" y de la formación de la hipótesis explicativa de la historia social. En relación con estas cuestiones, hay que discutir si la ciencia histórico-social procede por conceptos $y$, en este caso, con qué tipo de conceptos. Se debe averiguar si los conceptos adecuados a la ciencia histórico-social son los analfiticos o sintéticos, es decir, conceptos inducidos y situados históricamente, pero con capacidad explicativa de toda la historia social, - bien, conceptos cuya comprensión lógica se ciñe sólo al "individuo histórico", a una sociedad o época dada, y que en cuanto tales no son extrapolables a otras sociedades y tiempos y, por tanto, carecen de extensión y capacidad explicativa: ¿conceptos analítico-hipotéticos extensivos o conceptos sintéticos y encerrados de Weltanschauung? $O$, al contrario, ¿̨habrá de reconocerse que lo propio de la ciencia histórico-social es la vivencia, el sentimiento, la simpatía o endopatía, la "afinidad electiva", es decir, un acto de conocimiento inmediato y ateorético, cuya traducción borrosa, limitada e improductiva es el concepto racional analítico?

De igual manera, debe plantearse la cuestión de si a este nuevo género de ciencias compete la explicación causal o sólo la descripción de "lo 
esencial", "lo típico" y "lo peculiar" de una sociedad dada o de una época histórica. Y en el caso de que deban incluir la explicación causal, para poder constituirse como ciencias en sentido propio, habrá que preguntarse si el esquema de explicación será por causas o por fines, si se estructurará según un esquema causal determinista o según un esquema causal teleológico. $\mathrm{Y}$ habrá que preguntarse además, en caso de que se afirme la causalidad teleológica, si ésta es determinista o libre, necesaria o contingente, detectable empíricamente o reconstruible interpretativamente. En suma, los problemas acerca de si la constitución científica de las ciencias históricas y sociales sea "positiva", "dialéctica" o "hermenéutica"; los problemas de la "explicación causal" y de "la comprensión de sentido" y las cuestiones acerca de una posible y válida articulación o síntesis entre estos dos esquemas. Finalmente, como consecuencia de las respuestas que se den a toda esta constelación de interrogantes, se debe afrontar la cuestión crucial de si la ciencia histórico-social puede ser diferente e independiente de la filosofía práctica $y$, en particular, de la filosofía de la historia.

Como resultado de la teoría del conocimiento y de la epistemología de las ciencias histórico-sociales surgirán conceptos y enunciados acerca de la estructura y dinámica de la historia social humana. ¿Es la historia ante todo una historia de la producción material o de intereses "naturales" de poder o es una historia de la autoconciencia, de la cultura, de la libertad, de la moral? ¿Es la historia una conexión coherente y cohesionada que abraza, entrelaza e imbrica todos los espacios y tiempos sociales, por lo que se puede hablar con rigor de una "historia universal" o de una "conexión de sentido", o hay, en cambio, toda una pluralidad, contingencia y diferencia de historias particulares, locales, regionales, nacionales? La dinámica de la historia eprocede por evolución ordenada y progresiva de un positivo originario en estado inmediato o potencial, o bien procede por dialéctica negativa, mediante rupturas y conflictos, desarrollando un positivo terminal como su telos? Más aún, ¿̇se desarrolla en realidad algo en la historia, se puede hablar de una historia lineal y ascendente, o en realidad la historia es circular y clausurada, o sólo una masa de acontecimientos sin orden y dirección, mera contingencia y pura posibilidad? Y si se desarrolla algo, ¿cuál es su identidad, es el Espiritu absoluto, la naturaleza, la vida, la naturaleza humana, el espíritu nacional-popular, la conciencia y la libertad, la producción material...? $\mathrm{Y}$, en caso de desarrollo, ¿cuál es la relación entre el pasado y el presentefuturo, entre la tradición y la modernidad? ¿Es una relación del tipo "edad de oro" y decadencia temporal, de "clásico" y "romántico", de "arquetipo" unitario y especimenes limitados y cambiantes, o bien, al revés, de barbarie y civilización, de "estado natural" y "estado civil", de 
"minoría de edad" y "mayoría de edad", de irracionalidad oscura e ilustradición racional? ¿Es una relación del tipo "retorno a las fuentes", Phoenix, renovatio, reformatio, o bien de "exodo a nueva tierra y nuevo cielo", incipit vita nova?

Por último, ¿cuál es la articulación entre razón e historia, concepto y tiempo, teoría y práctica, ciencia-filosofía y política, los intelectuales y el poder? ¿Es la razón fuerza histórica, fuerza de transformación del mundo, fuerza política o, en cambio, es sólo conocimiento de las fuerzas actuantes en la historia, interpretación del mundo, quizá norma ilustrada de lo que deben o pueden ser las instituciones sociales, pero políticamente impotente? $\mathrm{Y}$ si se le concede una fuerza innovadora, transformadora, revolucionaria a la razón, ’esto se debe a que naturaleza e historia social son mera materia pasiva, disponible, funcional para el concepto teórico y la norma práctica de un sujeto espiritual trascendental que actúa sólo a partir de sí mismo y con la obligación congruente de actuar sólo a partir de sí mismo? $O$ bien, ¿esto se debe a que el concepto teórico y la norma práctica surgen y son producidos desde y por la dinámica misma de la historia social-natural, como sus momentos más avanzados, su frontera, y en los que la historia social "sabe" sus necesidades, contradicciones y límites y busca y proyecta, entonces, su solución de identidad y se trasciende en nuevas instituciones más satisfactorias y más universales? $O$, igualmente, ¿existe una causalidad propia y efectiva de la autoconciencia y libertad humanas en la historia social-natural?, ¿es la causalidad histórica la teleología intencional de los individuos y comunidades? $O$, en cambio, ¿autoconciencia y libertad humana son sólo ejecutores conscientes y responsables de una necesidad conocida que les pre-existe, los precondiciona y los arrastra en su movimiento causal intrinseco?

Éstos fueron algunos de los problemas que Kant y Hegel, los padres fundadores de la teoría y de la política de la modernidad alemana, ante la revolución racional, heredaron a los intelectuales y a los políticos alemanes de los siglos xIx y xx. Problemas que son dilemas, problemas cuyo nudo prefirió Marx desmadejarlo de un solo tajo, con "la inversión materialista". Pero, para aquellos pensadores y actores que pensaban, con o sin razón, que los problemas eran mucho más complejos y que la conceptualización y solución marxiana de los problemas era reductiva, se trató de un nudo que no se ha terminado aún de desatar, como lo muestra la obra de Dilthey, Weber y Carl Schmidt o la obra de la Escuela de Frankfurt, de E. Bloch y de J. Habermas, que desde Marx tratan de "reconstruir" críticamente la tradición de la Ilustración y del Historicismo, de Kant y Hegel, pero que, por el impacto de rebote de este ajuste de cuentas con la tradición, terminan también en una "reconstrucción del materialismo histórico" (J. Habermas). 